\title{
Academic Dishonesty in Medical Schools
}

Pius Musau

Moi University, School of Medicine, Department of Surgery and Anesthesiology

Correspondence to: Dr. Pius Musau P.0 Box 4606-30100, Eldoret, Kenya. Email: musau_pius@yahoo.com

\begin{abstract}
Background: Dishonesty can be found in all aspects of human interaction and is known to be rampant in educational institutions. Little is known about it in medical training and the characteristics of those involved. This study explores the factors that drive academic dishonesty among aspiring doctors. Objective: To establish the factors driving academic dishonesty among senior medical students. Design: Cross sectional survey using self-administered questionnaire. Setting: The School of Medicine, Moi University. Subjects: One hundred and fifty-six students in the clinical years of study. Results: Those who had past experience with academic dishonesty had a $70.4 \%$ chance of cheating in university compared to $58.9 \%$ for those not previously exposed. The odds ratio was 3.6 for males to be involved in academic dishonesty than females. Being aware of
\end{abstract}

\section{Introduction}

Academic dishonesty is a rampant activity stretching from basic to tertiary Kenyan institutions with 50$75 \%$ of students confessing to it (1). It is expected that with the rapid increase in the number of tertiary institutions and the ensuing stretch on the limited human and other resources, the quality of education may be diluted by academic dishonesty (2). There is no data to show how medical students compare to other university students on academic dishonesty including the characteristics (like past experience, witnessing others and peer pressure) of the medical students likely to engage in academic dishonesty. This not only affects the individual and the societal integrity but also the quality of future doctors. This paper explored the determinants of academic dishonesty among medical students in a School of Medicine in the Western part of Kenya.

\section{Methods}

Medical students in the clinical (4th, 5th and 6th) years of study were contacted through their academic dishonesty in the Medical School made it $86.3 \%$ likely that a student would participate. Having witnessed academic dishonesty in progress was the strongest predictor of likely involvement in cheating. Conclusion: The cheating medical student in the clinical years is likely to be a male in the early part of the study with similar previous experience, has witnessed cheating and believes that the classmates are actively equally involved.

Key words: Academic Dishonesty, Medical Training, Medical Students

Ann Afr Surg. 2017;14(1): 19-21.

DOI: http://dx.doi.org/10.4314/aas.v14i1.4

(C) 2017 Annals of African Surgery. This work is licensed under the Creative Commons Attribution 4.0 International License.

respective class representatives to anonymously fill an Institutional Ethics and Research Committee (IREC) approved 20-item self-administered questionnaire. The questionnaire captured the demographic data, some closed questions to be ticked according to preferred answers and the views of the students on various aspects of academic dishonesty ranked in a Likert scale of six levels starting with strongly agree to strongly disagree. The questionnaire had been pre-tested on 10 preclinical students and refined for clarity and objectivity. Academic dishonesty was described as any activity in a formal academic setting that results in undue advantage to those involved. The three classes had 270 students and 210 questionnaires were equally distributed. Respondents were kept anonymous. The filled questionnaires were submitted to the representatives who in turn returned them to the researcher. Collected data was transcribed into a sheet and entered for analysis using SPSS version 21. Subjective data were presented in frequencies, continuous data in range, mean and standard 
deviations and inferential statistics were considered significant at $\mathrm{p} \leq 0.05$. The results are presented in tabulated figures, odds, ratios and percentages.

\section{Results}

One hundred and fifty-six students returned the duly filled questionnaires, giving a response rate of $74.3 \%$. The male to female ratio was 1.3:1 with age range of 21 to 34 years and a mean \pm standard deviation of $24.1 \pm 1.8$ years. The offered definition of academic dishonesty was agreeable to $96.7 \%$ of the respondents. Twenty seven students (17.3\%) confessed to having participated in academic dishonesty while in secondary school. In the medical school, $75.6 \%$ had witnessed academic dishonesty while $60.9 \%$ were actively involved. Table 1 shows the distribution of these students in terms of gender, year of study, prior exposure to academic dishonesty and whether or not involved while in university.

\section{Table 1: Students' experience with academic} dishonesty

\begin{tabular}{|c|c|c|c|c|}
\hline Variable & \multicolumn{2}{|c|}{ Exposed in secondary } & \multicolumn{2}{|c|}{ Involved in University } \\
\hline Gender & Yes & No & Yes & No \\
\hline Male & 22 & 65 & 53 & 34 \\
\hline Female & 5 & 64 & 42 & 27 \\
\hline \multicolumn{5}{|c|}{ Year of study } \\
\hline $4^{\text {th }}$ & 11 & 31 & 26 & 16 \\
\hline $5^{\text {th }}$ & 8 & 59 & 47 & 20 \\
\hline $6^{\text {th }}$ & 8 & 39 & 22 & 25 \\
\hline
\end{tabular}

Males were 4.4 times likely to have been exposed to dishonesty in secondary schoolas compared to females. The odds ratio was 3.6. The chance of an exposed student being involved in dishonesty in university was $70.4 \%$ while the unexposed had a $58.9 \%$ chance. The proportions of exposure varied with the years of study with the fourth years being almost the same number of the exposed in the remaining two years of study (26.2\% vs. $28.9 \%)$.

Out of the students aware of ongoing academic dishonesty in the school, $86.3 \%$ were involved in academic dishonesty $(p=0.016)$. Majority of those aware of academic dishonesty (83.2\%) also believed that their classmates were participating $(p<0.001)$. A significant proportion (85.2\%) of those previously exposed to academic dishonesty also believed that the classmates were involved $(\mathrm{p}=0.026)$. Table 2 shows the students' level of prior exposure, awareness, participation and the perception on classmates.
Table 2: Level of prior exposure, awareness, participation and perception on classmates.

\begin{tabular}{|c|c|c|c|c|c|c|}
\hline Nature & \multicolumn{3}{|c|}{ Involved in University } & \multicolumn{3}{|c|}{ Classmates involved } \\
\hline Awareness & Yes & No & $P$ value & True & False & $P$ value \\
\hline Yes & 82 & 43 & \multirow{2}{*}{0.016} & 104 & 21 & \multirow{2}{*}{$<0.001$} \\
\hline No & 13 & 18 & & 2 & 29 & \\
\hline $\begin{array}{l}\text { Exposed in } \\
\text { secondary }\end{array}$ & Yes & No & $P$ value & True & False & $P$ value \\
\hline Yes & 19 & 8 & \multirow{2}{*}{0.187} & 23 & 4 & \multirow{2}{*}{0.026} \\
\hline No & 76 & 53 & & 83 & 46 & \\
\hline
\end{tabular}

A multivariate analysis of the independent predictors of likely involvement in academic dishonesty revealed having witnessed it in progress as the strongest of them all $(p=0.031)$.

\section{Discussion}

Academic dishonesty is rampant not only in Kenya but also other geographical settings and covers all stages of education from elementary to tertiary institutions (15). This study found that $17.3 \%$ of the medical students had prior experience with academic dishonesty in their secondary school days. As found by Davis and Ludvigson (6), this study also found that the students who had been exposed to cheating before university education were more likely to be involved in academic dishonesty. Noni and Swift also found that students who engage in and justify academic dishonesty, even once, are not only more likely to engage in it in the future but also likely to lead a life of dishonesty such as fraud and theft at the workplace (7).

The cheating student will take all sorts of forms and different studies have had different findings as concerns the gender; ranging from no difference to predominance of the male gender (8). In this study, the males were not only more exposed to cheating before joining university but also were the majority involved in this vice. It is thought that the males are more likely to engage in activities that take into their academic time as sports and partying and also perceive themselves to be at greater risk of losing in a paternalistic society if they get low grades, hence the greater temptation to engage in academic dishonesty. Bushway and Nash (3) indicated that those with lower actual school achievement cheat more while Whitley (8) found the reverse to be the case. It probably depends on the prevailing circumstances in terms of the extent of academic dishonesty over the years and measures instituted to contain it. In this study, the higher number of the junior students, and thus presumed lower actual school achievement compared to the senior students, most probably is due to the stated failure by mandated bodies to contain the malpractice, hence bigger 
numbers with the succeeding years. It might also reflect an earlier culture that considered competences to be more important than glittering fake certificates. Jude found that older students, females, and students with higher academic achievement are less likely to cheat, whereas students involved with many extracurricular activities are more likely to do so (9).

McCabe and colleagues quoted multiple studies before they themselves drew the conclusion from their study that the most decisive factor in a student's decision to cheat is his perception of his peers' relationship with academic dishonesty (10). In our study, students who were aware of ongoing academic dishonesty in the school and, particularly, those who had witnessed it in progress were more likely to also participate. It is in keeping with the understanding drawn out of a study by Sattler et al that when students realize cheating to be a norm, they all aspire to do it to not only avoid being disadvantaged but to also belong (11).

\section{Conclusion}

The cheating medical student in the clinical years is likely to:

1. Be a male in the early years who has had similar experience in secondary school.

2. Not only be aware of academic dishonesty in medical school but has also witnessed it.

3. Believe that the classmates are also actively involved.

\section{Recommendation}

The fight against academic dishonesty in Medical Schools should also consider means by which prior exposure in Secondary Schools is minimized since the exposed student not only participates but also believes that everybody else is involved. Medical Schools should have a wide range of measures to contain varied forms of academic dishonesty including enhancing lecturer: student ratios and instituting stringent punishments to discourage the practice.

\section{Acknowledgement}

I acknowledge the kind gesture and willingness of the medical students in the study who gave data without which this paper would not have been possible.

\section{References}

1. Akaranga SI, Ongong JJ. The Phenomenon of Examination Malpractice: An Example of Nairobi and Kenyatta Universities. Journal of Education and Practice 2013; 4(18): 87-96.

2. Sifuna DN. Some Reflections on the Expansion and Qualities of Higher Education in Public Universities in Kenya. Research In Post-compulsory Education 2010;15(4): 415-25.

3. Bushway,A ,Nash W.R. School Cheating Behavior. Review Of Educational Research 1997;47(4): 623

4. Simmons SC. Competing Notions of Authorship: A Historical Look at Students and Textbooks on Plagiarism and Cheating, in Perspectives on Plagiarism and Intellectual Property in the Postmodern World ed. Lise Buranen and Alice M. Roy (Albany: State University Of New York Press, 1999, 45).

5. Bachore, M. M. Academic Dishonesty/ Corruption in the Period of Technology: Its Implication for Quality of Education. Am. Educ. Res. J 2014; 2(11):1060-64.

6. Davis SF. Ludvigson, H.W. Additional Data on Academic Dishonesty and a Proposal for Remediation. Teaching of Psychology 1995; 22(2): 119-21.

7. Noni S, SwiftCO. An Examination of the Relationship between Academic Dishonesty and Workplace Dishonesty. Journal of Business Education 2001; 77(2): 69-77.

8. Whitley BE. Factors Associated with Cheating among College Students: A Review, Research in Higher Education 1998; 39(3): 252.

9. Jude, CA. Handbook for Deterring Plagiarism in Higher Education (Oxford: The Oxford Centre for Staff and Learning Development, 2002, 18.

10. McCabe DL, Trevino LK. Butterfield DL. Honor Code and other Contextual Influences on Academic Integrity: A Replication and Extension to Modified Honor Code Settings. Research In Higher Education 2002; 43(3):368.

11. Sattler S, Graeff P, Willen S. Explaining the Decision to Plagiarize: An Empirical Test of the Interplay between Rationality, Norms, and Opportunity. Deviant Behavior 2013; 34: 444-63. 